Supplement of The Cryosphere, 13, 2203-2219, 2019

https://doi.org/10.5194/tc-13-2203-2019-supplement

(C) Author(s) 2019. This work is distributed under

the Creative Commons Attribution 4.0 License.

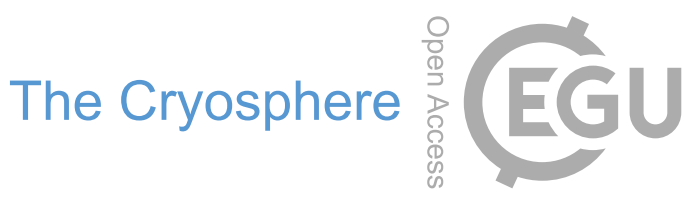

(c) (1)

Supplement of

\title{
Water tracks intensify surface energy and mass exchange in the Antarctic McMurdo Dry Valleys
}

\section{Tobias Linhardt et al.}

Correspondence to: Tobias Linhardt (tobias.linhardt@uni-bayreuth.de)

The copyright of individual parts of the supplement might differ from the CC BY 4.0 License. 


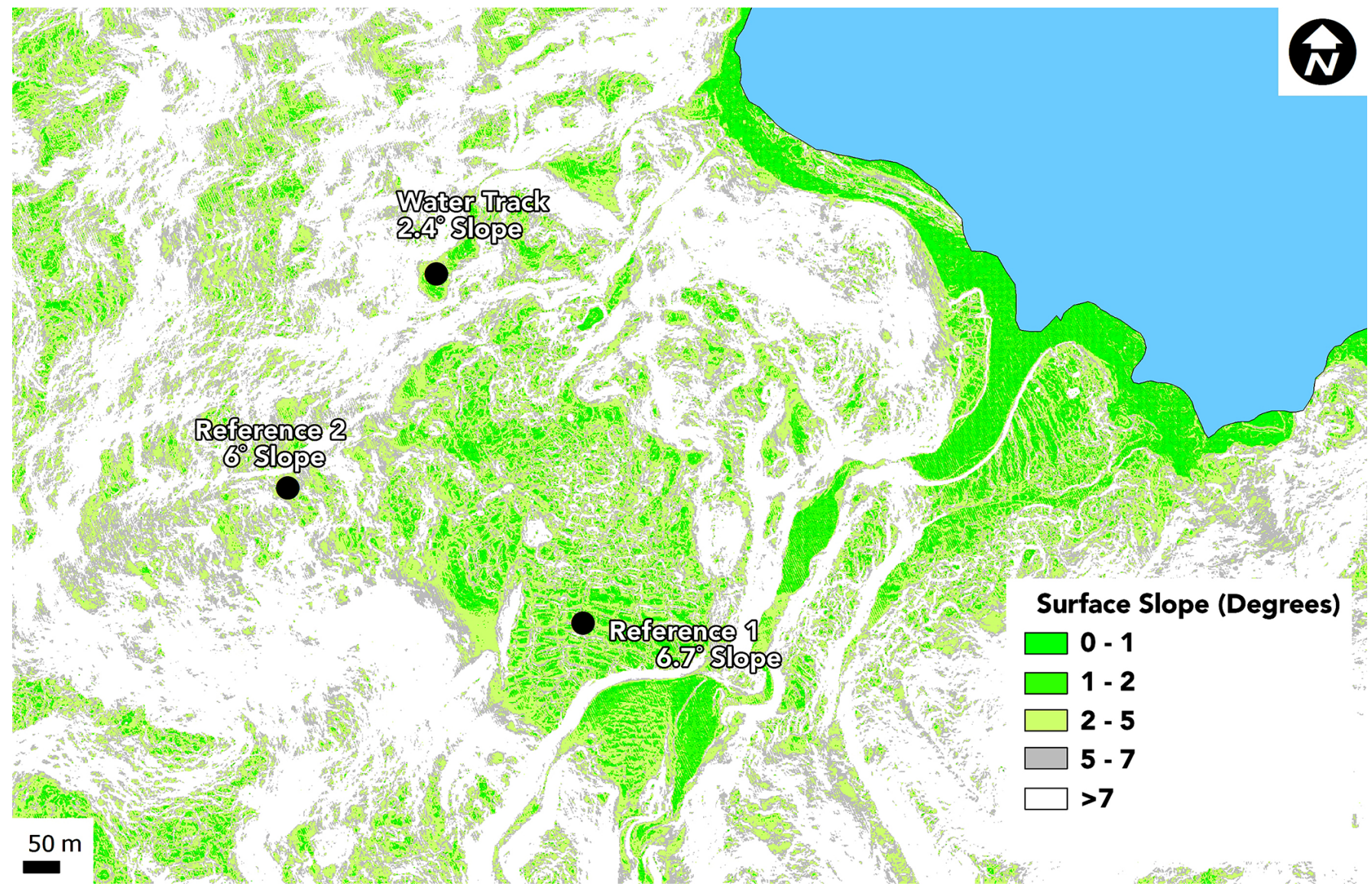

Figure S1 Slope map showing experimental sites in lower Taylor Valley, with slopes denoted for each site. LIDAR data are taken from Fountain et al. (2017). WT (Water Track), PLD (Reference 1, paleolake delta) and GT (Reference 2, glacial till). 
$\begin{array}{lllll}\text { Dec } 27 & \text { Jan } 06 & \text { Jan } 16 & \text { Dec } 27 & \text { Jan } 06\end{array}$
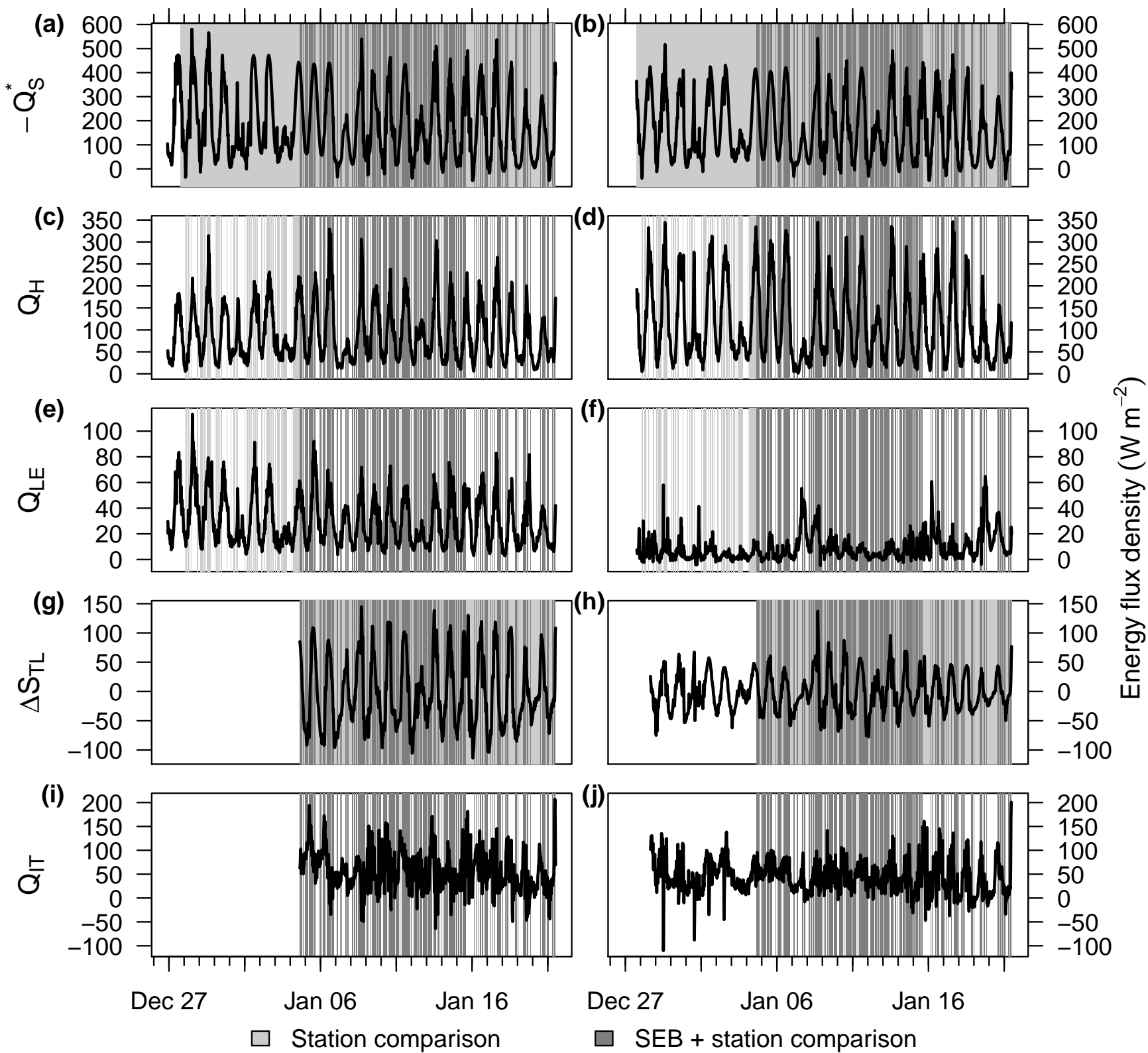

$\square$ SEB + station comparison

Figure S2 Time series of gap-filled surface energy balance components over the whole measurement period for WT (water track) and NWT (non-water track). Net radiation $-Q_{S}^{*}(\mathbf{a}-\mathbf{b})$, sensible heat flux $Q_{H}(\mathbf{c}-\mathbf{d})$, latent heat flux $Q_{L E}(\mathbf{e}-\mathbf{f})$, heat storage change in thawed layer $\Delta S_{T L}(\mathbf{g}-\mathbf{h})$, soil heat flux at ice table depth $Q_{I T}(\mathbf{i}-\mathbf{j})$. Bright and dark gray shading denotes data used for inter-station comparison of individual surface energy balance components. Dark gray shading shows data used for calculation of surface energy balances, which is the same selection for all energy balance components. For sign conventions see caption to Fig. 5 in the article. 

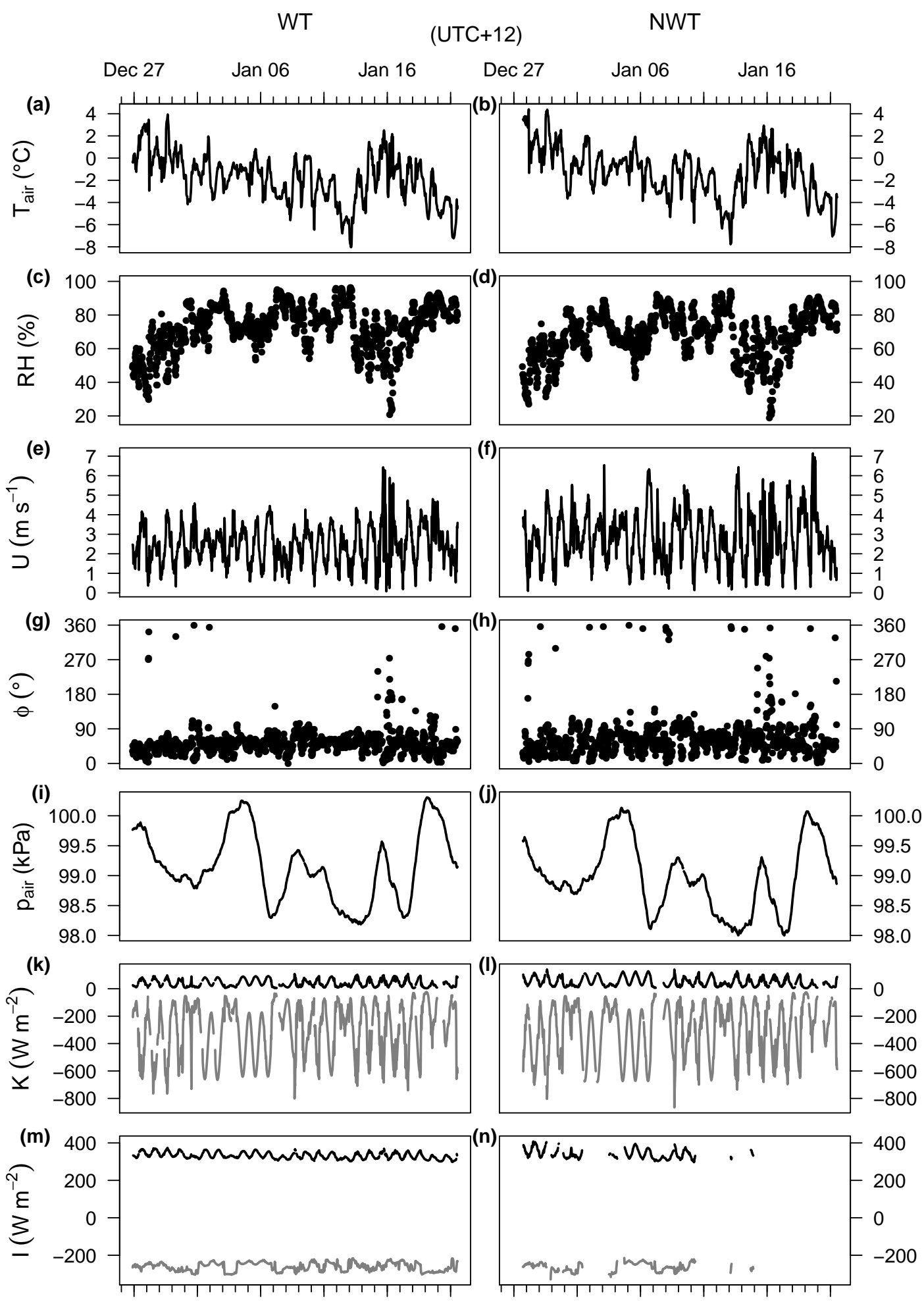

$$
\begin{array}{llllll}
\operatorname{Dec} 27 & \operatorname{Jan} 06 & \operatorname{Jan} 16 & \operatorname{Dec} 27 & \operatorname{Jan} 06 & \operatorname{Jan} 16 \\
& \mathbf{\square} & \text { upwelling radiation }(\mathrm{k}-\mathrm{n}) & \square & \text { downwelling radiation }(\mathrm{k}-\mathrm{n})
\end{array}
$$

Figure S3 Time series of meteorologic measurements over the whole recording period for WT (water track) and NWT (nonwater track). Air temperature $T_{\text {air }}(\mathbf{a}-\mathbf{b})$, relative humidity $R H(\mathbf{c}-\mathbf{d})$, mean horizontal wind speed $U(\mathbf{e}-\mathbf{f})$, mean azimuth wind direction $\phi(\mathbf{g}-\mathbf{h})$, barometric air pressure $p_{\text {air }}(\mathbf{i}-\mathbf{j})$, up- and downwelling shortwave radiation $K(\mathbf{k}-\mathbf{l})$ and longwave radiation $I(\mathbf{m}-\mathbf{n})$. 
WT

NWT

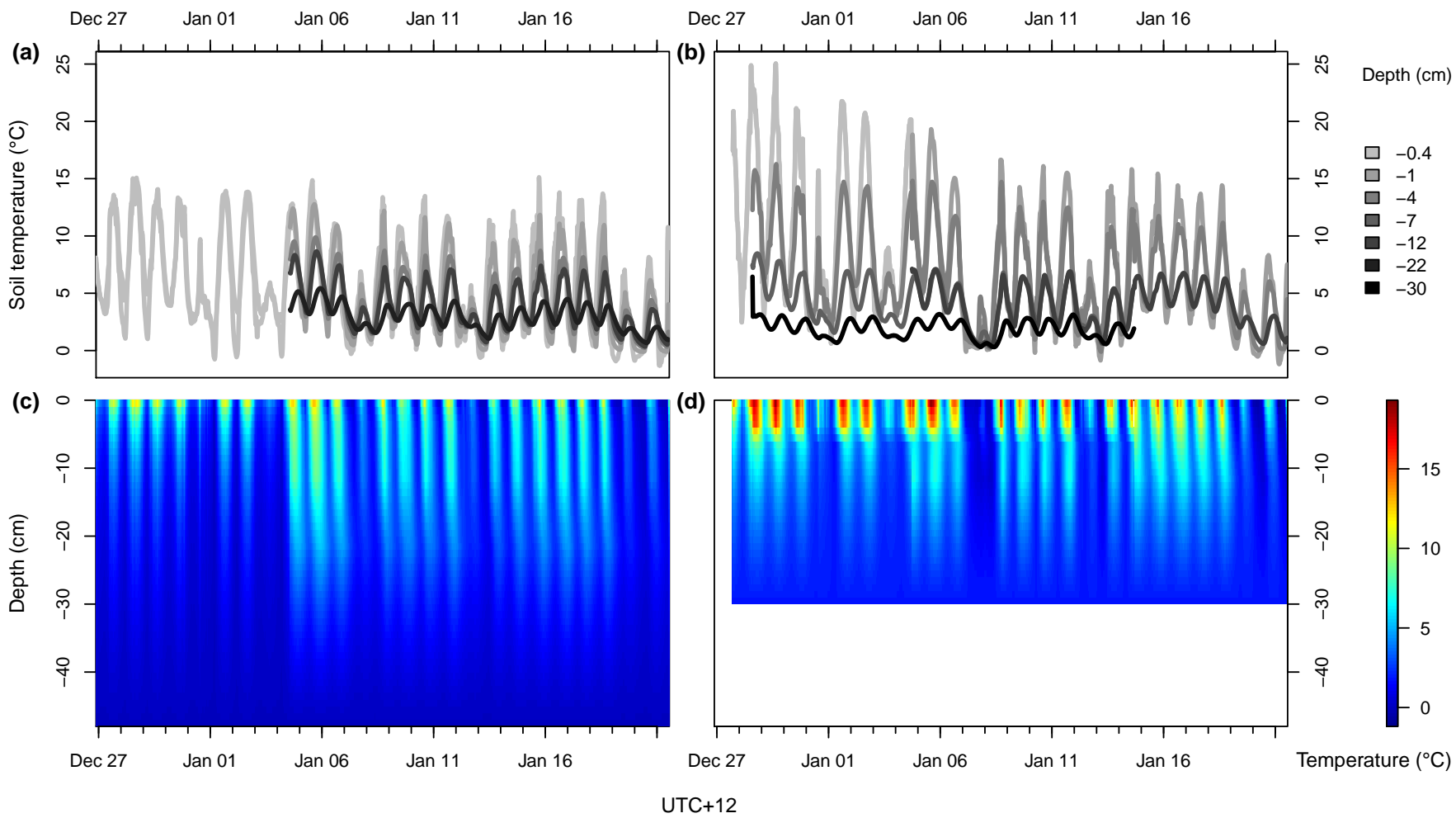

Figure S4 Time series of soil temperatures over the whole recording period for WT (water track) and NWT (non-water track). Soil temperature measurements $(\mathbf{a}-\mathbf{b})$ and soil temperature profiles with logarithmic interpolation between measurements $(\mathbf{c}-$ d). 


\section{References}

Fountain, A. G., Fernandez-Diaz, J. C., Obryk, M., Levy, J., Gooseff, M., van Horn, D. J., Morin, P., and Shrestha, R.: High-resolution elevation mapping of the McMurdo Dry Valleys, Antarctica, and surrounding regions, Earth Syst. Sci. Data, 9, 435-443, https://doi.org/10.5194/essd-9-435-2017, 2017. 